\title{
Evaluation of Serum Nitric Oxide Levels and Some Biochemical Parameters in Patients with Liver Cirrhosis
}

\author{
Hemn Jameel Majeed, Parween Abdulsamad Ismail* and Lutfia Muhammad Hassan \\ Department of Chemistry, University of Salahaddin, Iraq
}

*Corresponding author: Parween Abdulsamad Ismail, Department of Chemistry, College of Education, University of Salahaddin, Erbil, Iraq.

To Cite This Article: Parween Abdulsamad Ismail, Evaluation of Serum Nitric Oxide Levels and Some Biochemical Parameters in Patients with Liver Cirrhosis. 2020 - 8(1). AJBSR.MS.ID.001227. DOI: 10.34297/AJBSR.2020.08.001227.

Received: 眥 March 03, 2020; Published: 㘹 March 10, 2020

\begin{abstract}
Background: Liver Cirrhosis occurs as a result of necrosis of hepatic cells followed by fibrosis and formation of nodule. It is associated with changes in various biochemical parameters and various clinical manifestations in the patients. The objective of the current study to assessment the level of nitric oxide and some biochemical parameters in patients with liver Cirrhosis disease.

Methods: A total of 37 cases diagnosed clinically and biochemically as Cirrhosis disease and 35 age-matched controls were enrolled in the study. Biochemical analyses were carried out which included estimation the level of serum Nitric oxide, albumin, Aspartate Transaminase (AST), Alanine Transaminase (ALT), $\gamma$-Glutamyl Transpeptidase (GGT), Adenosine Deaminase (ADA) and Alkaline Phosphatase (ALP).

Results: The serum Nitric oxide (NO) was significantly $(\mathrm{p}<0.001)$ higher in the study group than in the control group, Also the results demonstrated significantly higher activities of ADA ( $<<0.001)$, GGT $(\mathrm{p}<0.0001)$, ALP $(\mathrm{p}<0.001)$ and AST $(\mathrm{p}<0.0001)$, ALT( $<<0.0001)$ in liver cirrhotic patients in comparison with control group.
\end{abstract}

Conclusion: Elevation of Nitric Oxide concentration could be used a potential diagnostic marker for Liver Cirrhosis.

Keywords: Liver Cirrhosis, Nitric Oxide, Liver Enzymes, Chronic Liver Diseases, Portal Hypertension, Cirrhotic Cardiomyopathy, Pulmonary Vascular Abnormalities, Serum Enzymes, Chronic Active Hepatitis, Arteriovenous Inosculation

\section{Introduction}

Chronic liver diseases may possibly classify into liver cirrhosis and chronic active hepatitis. Liver illnesses it could be attended by portal hypertension. Several systemic changes may occur with liver cirrhosis and portal hypertension [1]. These abnormalities changes of patients with liver cirrhosis have been stated to elevate the risk of hyperdynamic circulation like (ascites, edema, hepatorenal syndrome, etc.). Furthermore, Liver cirrhosis is related to many cardiovascular irregularities such us cirrhotic cardiomyopathy, and pulmonary vascular abnormalities [2,3]. With the progression of the liver cirrhosis the metabolic impairment leads to fibrosis of the liver and change efficient disturbances of various organ systems include heart, kidneys, lungs, immune systems and other organ systems [4]. In addition, with the cirrhotic apparent, the cardiac mitochondrial functions reduce in breathing regulator ratio and rise mitochondrial inflammation [5].

Nitric Oxide (NO) is one of the most abundant products induced with the catabolism of L-arginine in various mammalian cells, by the action of enzymes that catalyze and regulate synthesis and catabolize arginine. These induced and in certain alterations in the nitric oxide synthase play main role in metabolic outcome of arginine in health and disease subject [6,7]. In the beginning, the alteration of cell NO releases was established mostly in the cardiovascular system, but nowadays the ultimate role and twin effects (low concentration and high concentration) had been recognized in various organizations of human body [8]. The objective of the recent study was purposed to determine the serum levels of Nitric Oxide in patient whom 
suffering with the liver cirrhosis and to exhibit their correlation with the extra considerations such us serum albumin level and Serum enzymes: ALP, AST, GGT and ADA.

\section{Materials and Methods}

\section{Study Subjects}

A total of thirty-seven cases which were diagnosed clinically and biochemically as Liver Cirrhosis and thirty-five healthy subjects were participated in the study. Their ages ranged from 3662 years. A total of thirty-seven serum samples were obtained from individuals diagnosed with Liver Cirrhosis. Their ages ranged from 36-62 years.

\section{Collection of Blood Samples}

Approximately $5 \mathrm{ml}$ of venous blood was collected from individuals. After coagulation, all samples were centrifuged at $3000 \mathrm{rpm}$ for 10 minutes and sera were stored at $-70^{\circ} \mathrm{C}$ until analyzed.

\section{Biochemical Analysis}

\section{Assay of Nitric oxide concentration}

Nitric oxide concentration has been estimated by using sandwich enzyme immunoassay (ELISA) technique (BIOSOURCE, Europe S.A., Belgium, Lot No.051501/B; 060601).

\section{Principle of Human Nitric Oxide (NO) ELISA kit}

This experiment was used double-sandwich ELISA technique and the ELISA Kit provided was typical. The pre-coated antibody was human NO monoclonal antibody and the detecting antibody was polyclonal antibody with biotin labeled. Samples and biotin labeling antibody were added into ELISA plate wells and washed out with PBS or TBS. Then Avidin-peroxidase conjugates were added to ELISA wells in order; Use TMB substrate for coloring after reactant thoroughly washed out by PBS or TBS. TMB turns into blue in peroxidase catalytic and finally turns into yellow under the action of acid. The color depth and the testing factors in samples were positively correlated.

\section{Assay of Liver enzymes activities}

Liver enzymes activities which included $\gamma$ - Glutamyl Transpeptidase (GGT), Alkaline Phosphatase (ALP), Adenosine deaminase (ADA), Aspartate Transaminase (AST) (GPT) and Alanine Transaminase (ALT) (GOT) were estimated spectrophotometrically using RANSOD $®$ (RANDOX BRAZIL Ltd.) kits, according to the manufacturer's specifications. kits.

\section{Statistical Analysis of Data}

Results are expressed as mean \pm SD. Statistical comparisons were carried out using (SPSS, Chicago, Il, USA). and P-value of $<0.05$ was satisfactory significant.

\section{Results}

Theresultsare illustrated in Table 1 and Figure 1. Themean serum NO in liver cirrhosis, and control subjects were $90.34 \pm 8.45 \mathrm{mmol} / \mathrm{L}$ and $45.01 \pm 4.27 \mathrm{mmol} / \mathrm{L}$, respectively. Statistical evaluation showed that nitric oxide levels were elevated in case groups compared with the control group $(\mathrm{p}<0.0001)$. Also serum albumin, Aspartate Transaminase (AST), Alanine Transaminase (ALT), $\gamma$-Glutamyl Transpeptidase (GGT), Adenosine Deaminase (ADA) and Alkaline Phosphatase (ALP) activities are significantly increased $(\mathrm{P}<0.05$, $\mathrm{P}<0.0001, \mathrm{P}<0.0001, \mathrm{P}<0.0001, \mathrm{P}<0.001$ respectively) in patients with liver cirrhosis as compared to control samples.

\section{Discussion}

Fibrogenesis, inflammation and necrosis are the most alteration of liver mechanism process which causes the conversion from prolonged liver disease to cirrhosis. These changes typically happen due to spreading of nodular revival bounded by thick fibrotic septa with following parenchymal cell elimination and collapse of hepatic vascular construction [9]. In addition, the disturbances of the hepatic architecture produced by cirrhotic process increase the intra-hepatic resistance against portal blood flow, which the main issue is foremost to portal hypertension. Portal hypertension is a most abundant and terrible obstacle of people suffering chronic liver illness [10]. The pathological condition resulting from a portal hypertension which has happened in consequence of destruction to the portal veins is splanchnic overcrowding and opening of arteriovenous inosculation, which that finally attribute to oedema, ascites, splenomegaly etc.

Furthermore, concerning splanchnic arteriolar vasodilatation which will causes portal hypertension facilitated by NO and act to fill arteriolar vascular cavity, as well as making salt and water retention due to stimulating antidiuretic hormone [2]. Our study showed increased serum concentration of Nitric Oxide in patients with cirrhosis. Several investigators also demonstrated that serum NO concentrations are increased in hepatic cirrhosis [11-13]. The best explanation for increasing the NO concentrations is that differences in the degree of inflammation and fibrosis may cause differences in serum nitrite and nitrate levels The initial cause of excess production of nitric oxide is not known, whereas portal venous hypertension, which increases shear stress and up-regulates endothelial nitric oxide synthase, no doubt involved to nitric oxide overproduction $[14,15]$. The anatomic sites of the enhanced NO synthesis and release remain unclear. Evidence suggests that the activity of NO synthase activity may be upregulated at different sites, including the jejunum, gastric mucosa, and esophageal mucosa [16-19].

The levels of nitric oxide are higher in portal venous plasma than in peripheral venous plasma in patients with cirrhosis, suggesting elevated splanchnic production of nitric oxide [12]. The 
activity of nitric oxide synthase in polymorphonuclear cells and monocytes was elevated in patients who had cirrhosis. These cells mainly contain the inducible type of nitric oxide synthase, a finding that provides evidence that this type of the enzyme may have a role in peripheral vasodilatation in patients with cirrhosis [19]. Nitric Oxide which has been recognized as the utmost important vasodilator of hepatic vascular nature regulation is formed by endothelial cells. It is generally formed from the metabolism of guanidine group of arginine [20,2]. In the recent study, our results found significantly higher levels of NO in the patients with liver cirrhotic group than in the control group (Figure 1).

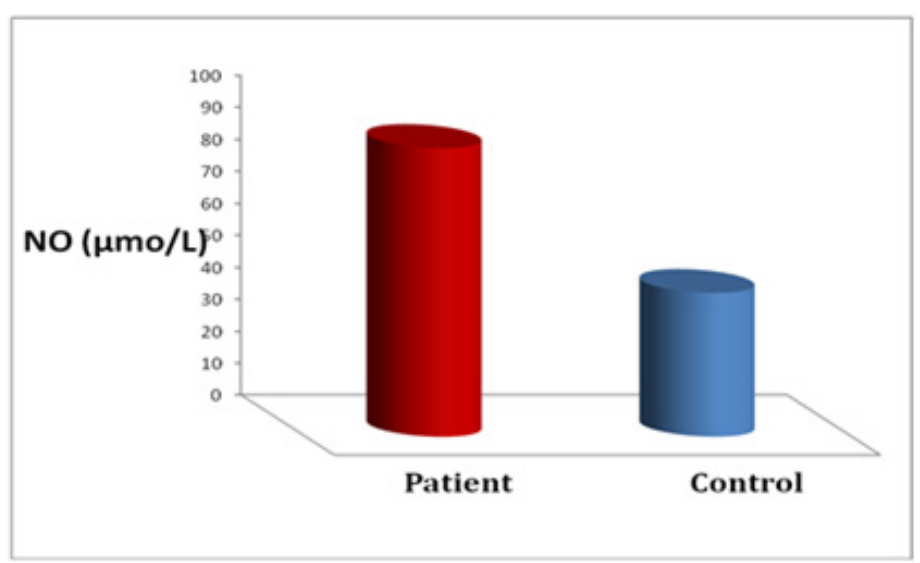

Figure 1: Mean values of serum NO in control and patients with liver Cirrhosis groups.

The various studies all agreed that serum NO concentrations are raised in liver cirrhosis $[1,2,5]$. Despite the anatomic and the mechanisms of the enhanced NO releases during cirrhosis is remained unclear and difficult to analyses. Confirmation proposes that at different sites, such as esophageal mucosa, gastric mucosa, and jejunum, NO synthase activity can be uncontrolled, and the activity of erythrocyte adversely related with the serum level of NO in liver cirrhotic patients [21]. The activity of serum ADA is significantly increased $(\mathrm{p}<0.001)$ in patients with liver cirrhosis compared to normal healthy individuals in all age groups. The data are in line with earlier results respectively [22,23]. The diagnosis of organ disease is aided by estimation of several non-functional plasma enzymes characteristic of that tissue or organ. The quantity of enzymes produced depends on the degree of cellular damage, the concentrations of the intracellular enzymes and the mass of affected tissue.

The cause of the damage (viral infection, hypoxia, surgical, chemical, or mechanical trauma) has no bearing on the enzymes released into blood circulation. The levels of the enzymes released reflects the severity of the damage. Mild inflammatory conditions are likely to release cytoplasmic enzymes whereas necrotic conditions yield mitochondrial enzymes as well. The use of appropriate normal ranges is important in assessing abnormal levels of plasma enzymes. Concerning liver injury, not liver normally functions are referred to measurements each of the Aspartate Aminotransferase (AST), Alanine Aminotransferase (ALT) and Alkaline Phosphatase (ALP). These laboratory measurement parameters are extremely reproducible. Therefore, hepatic cirrhosis as a last stage of liver disease or hepatic illnesses is required to assess and potential evaluation of AST, ALT and ALP.

In addition, the elevation of $\gamma$-Glutamyl Transferase (GGT) or ALP fractionation may trust an elevated ALP level of hepatic origin. Despite, AST is elevated in the liver dysfunctions, but it is not considered the more specific marker of hepatocellular damage, because it is present in other organs rather than liver including heart, brain, kidney and skeletal muscle. But ALT is more specific marker than AST, since it is existing primarily in the liver [24]. Table 1 shows significantly elevated level of GGT, ADA, ALP, ALT and AST in hepatic cirrhosis patients as compared to control group. GGT is very sensitive and reliable enzyme to identify liver injury in both intra and extra hepatic failure, due to it is existence in the cell membranes of hepatobiliary scheme. In different kinds of liver disease such as viral hepatitis, cholestasis and alcoholic liver disease the value of GGT is increases up to 5 times to 15 times upper than normal values [25]. However, in our study persistence elevation of GGT is changed from $63 \pm 11.67$ controls to $187 \pm 35.09$ as an indicator of cirrhosis.

Table 1: (Mean \pm SD) of Biochemical parameters in liver cirrhotic patients and control group.

\begin{tabular}{|c|c|c|c|}
\hline Parameters & Control & Patients & P-value \\
\hline Albumin(gm/dl) & $4.8 \pm 0.68$ & $2.43 \pm 0.47$ & P $<0.05$ \\
\hline GGT(IU/L) & $63 \pm 11.67$ & $187 \pm 35.09$ & P $<0.0001$ \\
\hline
\end{tabular}




\begin{tabular}{|c|c|c|c|}
\hline ADA(IU/L) & $15.07 \pm 1.92$ & $48.01 \pm 6.40$ & $\mathrm{P}<0.001$ \\
\hline ALP(IU/L) & $274 \pm 18.50$ & $340 \pm 25.01$ & $\mathrm{P}<0.001$ \\
\hline ALT(IUL) & $30.5 \pm 7.22$ & $70.02 \pm 27.35$ & $\mathrm{P}<0.0001$ \\
\hline AST(IUL) & $27.91 \pm 5.71$ & $80 \pm 27.12$ & $\mathrm{P}<0.0001$ \\
\hline
\end{tabular}

Increasing activities of plasma specific enzyme like ALT, AST, ADA and ALP considered as a feature diagnostic of hepatic diseases, subsequently enzymes are secreted into the bloodstream after the worsening of the liver organ. Despite releasing these mitochondrial and cytoplasmic enzymes into serum and others like Lactate Dehydrogenase (LDG), cholesterol, triglycerides, serum lipid profile and lipoproteins are used to estimate the status of liver function, while an elevation of transaminase enzyme more than two times folded is considered as a marker index of liver cirrhosis and hepatotoxicity [26]. In this study, all the ADA, ALP and alanine transaminase as well as aspartate transaminase enzymes raised from $(15.07 \pm 1.92,274 \pm 18.50,30.5 \pm 7.22 \& 27.91 \pm 5.71)$ to $(48.01 \pm 6.40$, $340 \pm 25.01,70.02 \pm 27.35$ and $80 \pm 27.12$ ) respectively.

Albumin is a family of spherical proteins produced in the liver and is closely attendant with the systems of pathophysiology in different forms of liver disease. Therefore, it has an important role in the controlling fluid spreading in the body [27]. The result, in the current study shows considerably decrease concentration of serum albumin in patient group (Table 1). This could cause by the changing qualitatively in albumin structure and not purely a quantitative decrease which is responsible for the defeat of it is physiological role that alters the basic knowledge of the processes that possibly cause significantly reduced albumin functioning in liver disease. Albumin, bilirubin, and time of prothrombin are hepatocellular function indicators that can be significantly influenced by extrahepatic factors [28].

\section{Conclusion}

Increased levels of nitric oxide contributed to the hemodynamic changes occur in patients of liver cirrhosis. Indicate that nitric oxide has a pathophysiological role in liver cirrhosis.

\section{References}

1. Liu H, Gaskari SA, Lee SS (2006) Cardiac and vascular changes in cirrhosis: pathogenic mechanisms. World J Gastroenterol 12(6): 837842.

2. Deshmukh A, More UK, Tilak MA, Sontakke AN, Deshmukh UD (2013) Role of Nitric Oxide in liver cirrhosis. Indian J of basic and applied medical res 2(6): 546-550.

3. Al Hamoudi WK (2010) Cardiovascular changes in cirrhosis: pathogenesis and clinical implications. Saudi J Gastroenterol 16(3): 145153.

4. Møller S, Henriksen JH, Bendtsen F (2014) Extrahepatic complications to cirrhosis and portal hypertension: haemodynamic and homeostatic aspects. World J Gastroenterol 20(42): 15499-15517.

5. Amirtharaj GJ, Natarajan SK, Pulimood A, Balasubramanian KA, Venkatraman A, et al. (2017) Role of oxygen free radicals, nitric oxide and mitochondria in mediating cardiac alterations during liver cirrhosis induced by thioacetamide. Cardiovasc Toxicol 17(2): 175-184.

6. Wu G, Morris SM (1998) Arginine metabolism: nitric oxide and beyond. Biochem J 336(1): 1-17.

7. Moshage H, Kok B, Huizenga JR, Jansen PL (1995) Nitrite and nitrate determinations in plasma: a critical evaluation. Clin Chem 41(6): 892896.

8. Antosova M, Plevkova J, Strapkova A, Buday T (2012) Nitric oxideimportant messenger in human body. Open Journal of Molecular and Integrative Physiology 2(3) 98.

9. Tsochatzis EA, Bosch J, Burroughs AK (2014) Liver cirrhosis. The Lancet 383(9930) 1749-1761

10. Bosch J, Abraldes JG, Fernández M, García Pagán JC (2010) Hepatic endothelial dysfunction and abnormal angiogenesis: new targets in the treatment of portal hypertension. J Hepatol 53(3): 558-567.

11. Vallance P, Moncada S (1991) Hyperdynamic circulation in cirrhosis. A role for nitric oxide. Lancet 337(8744): 776-778.

12. Guarner C, Soriano G, Thomas A, Bulbena O, Novella MT, et al. (1993) Increased serum nitrite and nitrate levels in patients with cirrhosis: relationship to endotoxemia. Hepatology 18(5): 1139-1143.

13. Genesca J, Gonzalez A, Sagura R, Catalan R, Marti R, et al. (1999) Interleukin-6, nitric oxide, and the clinical and hemodynamic alterations of patients with liver cirrhosis. Am J Gastroenterol 94(1): 169-177.

14. Albillos A, Rossi I, Cacho G, Martínez MV, Millán I, et al. (1995) Enhanced endothelium-dependent vasodilatation in patients with cirrhosis. Am J Physiol 268(3): 459-464.

15. Battista S, Bar F, Mengozzi G, Zanon E, Grosso M, et al. (1997) Hyperdynamic circulation in patients with cirrhosis: direct measurement of nitric oxide levels in hepatic and portal veins. J Hepatol 26(1): 75-80.

16. Kanwar S, Kubes P, Tepperman BL Lee S (1996) Nitric oxide synthase activity in portal hypertensive and cirrhotic rats. J Hepatol 25(1): 85-89.

17. Ohta M, Tanoue K, Tarnawski AS, Pai R, Itani RM, et al. (1997) Overexpressed nitric oxide synthase in portal-hypertensive stomach of rat: a key to increased susceptibility to damage? Gastro-enterology 112(6): 1920-1930.

18. Heidebaugh JJ, Brudevly M (2006) Cirrhosis and chronic liver failure: Part I Diagnosis and evaluation. Am Fam Physician 74(5): 756-762.

19. Pilette C, Moreau R, Sogni P, Kirstetter P, Cailmail S, et al. (1996) Hemodynamic and hormonal responses to long-term inhibition of nitric oxide synthesis in rats with portal hypertension. Eur J Pharmacol 312(1): 63-68.

20. García Pagán JC, Gracia Sancho J, Bosch J (2012) Functional aspects on the pathophysiology of portal hypertension in cirrhosis. Journal of hepatology 57(2): 458-461.

21. Koruk M, Aksoy H, Akçay F, Onuk MD (2002) Antioxidant capacity and nitric oxide in patients with hepatic cirrhosis. Annals of Clinical \& Laboratory Science 32(3): 252-256.

22. Takahashi M, Arai A, Ohashi T, Wakayama Y, Satsuta K, et al. (1984) Studies on the serum adenosine deaminase activity test in patients with hepatitis. Nippon Ika Diagaku Zasshi 51(6): 768-771.

23. Wang JL, Yuan SY, Shao JF (1986) Determination of serum adenosine deaminase: its diagnostic value in jaundice and liver fibrosis. Zhonghua Nei ke Za Zhi 25(2): 79-81. 
24. Kwo PY, Cohen SM, Lim JK (2017) ACG clinical guideline: evaluation of abnormal liver chemistries. The American journal of gastroenterology 112(1): 18-35.

25. Hyder MA, Hasan M, Mohieldein AH (2013) Comparative levels of ALT, AST, ALP and GGT in liver associated diseases. European journal of experimental biology 3(2): 280-284

26. Contreras Zentella ML, Hernández Muñoz R (2016) Is liver enzyme release really associated with cell necrosis induced by oxidant stress? Oxid Med Cell Longev 2016: 3529149.
27. Bernardi M, Ricci CS, Zaccherini G (2014) Role of human albumin in the management of complications of liver cirrhosis. J Clin Exp Hepatol 4(4): 302-311.

28. Kumar PA, SuBramanian K (2016) The role of ischemia modified albumin as a biomarker in patients with chronic liver disease. J Clin Diagn Res 10(3): 9-12. 